\title{
Efficacy of cisplatin/pemetrexed with bevacizumab to treat advanced lung adenocarcinoma with different drive genes: case report and literature review
}

\author{
This article was published in the following Dove Press journal: \\ OncoTargets and Therapy \\ 26 July 2016 \\ Number of times this article has been viewed
}

\author{
Haiyong Wang ${ }^{1,2}$ \\ Hui Zhu² \\ Li Kong ${ }^{2}$ \\ Jinming $\mathrm{Yu}^{2}$
}

'Department of Oncology, School of Medicine, Shandong University, ${ }^{2}$ Department of Radiation Oncology, Shandong Cancer Hospital Affiliated to Shandong University, Shandong Academy of Medical Sciences, Jinan, Shandong, People's Republic of China
Correspondence: Jinming Yu Department of Radiation Oncology, Shandong Cancer Hospital affiliated to Shandong University, Shandong Academy of Medical Sciences, 440 Ji Yan Road, Jinan, Shandong, 250117, People's

Republic of China

Tel +86 53I 87984777

Fax +8653187984079

Email sdyujinming@I26.com
Background: Bevacizumab combined with chemotherapy has become the first-line therapy in advanced nonsquamous non-small-cell lung cancer (NSCLC). However, few studies have focused on cisplatin/pemetrexed with bevacizumab as the first-line therapy to treat advanced nonsquamous NSCLC. Importantly, whether the epidermal growth factor receptor (EGFR) mutations or anaplastic lymphoma kinase (ALK) rearrangements can influence the efficacy of bevacizumab in combination with chemotherapy is very interesting. Herein, we report three cases with different types of gene drives in advanced nonsquamous NSCLC.

Case presentation: In the first case, a patient presented with wild-type EGFR and negative ALK rearrangement. In the second case, a patient presented with wild-type EGFR and positive ALK rearrangement. In the third case, a patient presented with negative ALK rearrangement and mutated EGFR in exon 19.

Conclusion: We speculate that bevacizumab in combination with cisplatin/pemetrexed as the first-line therapy is well tolerated and results in a clinically meaningful treatment benefit, irrespective of the gene drive type in advanced nonsquamous NSCLC. However, more data are needed to confirm the relationship.

Keywords: case reports, lung cancer, cisplatin/pemetrexed, bevacizumab

\section{Introduction}

Non-small-cell lung cancer (NSCLC) is one of the most common carcinomas in the world. ${ }^{1}$ Patients with advanced NSCLC have a poor prognosis, with 4-6 months median progression-free survival (PFS) and 8-10 months median overall survival (OS). ${ }^{2-4}$ Chemotherapy is the preferred option for advanced NSCLC, and platinum-based doublet chemotherapy is the internationally recognized standard for treating advanced NSCLC. 5,6 However, the efficacy of traditional chemotherapy has reached a plateau. With the development of molecular biology and cellular biology, targeted therapies bring hope to patients with NSCLC. Patients harboring epidermal growth factor receptor (EGFR) mutations or anaplastic lymphoma kinase (ALK) rearrangements may benefit from treatment with tyrosine kinase inhibitors or ALK inhibitors. ${ }^{7,8}$ In addition, bevacizumab, one of the most widely used drugs of targeted therapy, has been the first-line therapy in combination with chemotherapy in advanced nonsquamous NSCLC. ${ }^{9}$ However, few studies have focused on the combination of bevacizumab with pemetrexed/cisplatin. In addition, the correlation between EGFR mutations or ALK rearrangements and the efficacy of bevacizumab in combination with chemotherapy has been problematic in 

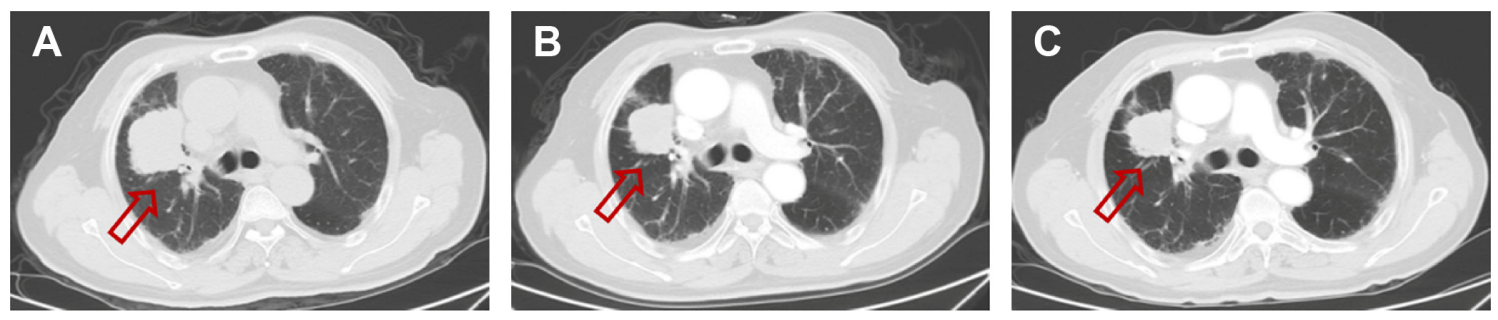

Figure I Case I.

Notes: (A) Prior to therapy, chest CT scan shows a primary mass (arrow) in the right lung. (B) After two cycles of therapy, chest CT scan shows significant shrinkage of the mass (arrow). (C) After four cycles of therapy, chest CT scan shows further shrinkage of the mass (arrow), although not obvious.

Abbreviation: $\mathrm{CT}$, computed tomography.

clinical practice. In our study, we share three case reports. In the first case, a patient presented with no EGFR mutations and ALK rearrangements. In the second case, we present a patient who has no EGFR mutations but has ALK rearrangements. While in the third case, we present a patient who has EGFR mutations but has no ALK rearrangements.

\section{Case reports}

This study was approved by the Ethics Committee of Shandong Cancer Hospital, and all patients signed informed consent forms for procedures to be performed and the reporting of their results.

\section{Case I}

A 69-year-old man presented to Shandong Cancer Hospital. The right lung mass was found by computed tomography (CT) scan 9 months ago, when the patient underwent a routine physical examination (Figure 1A). CT-guided percutaneous needle biopsy of the lung mass proved adenocarcinoma, and the gene detection showed that the EGFR was wild type and the ALK rearrangement was negative. The patient received bevacizumab $(7.5 \mathrm{mg} / \mathrm{kg})$, cisplatin $\left(75 \mathrm{mg} / \mathrm{m}^{2}\right)$, and pemetrexed $\left(500 \mathrm{mg} / \mathrm{m}^{2}\right)$ administered every 3 weeks. During the treatment, digestive tract reaction and myelotoxicity were well tolerated. Chest $\mathrm{CT}$ showed significant shrinkage of the primary mass after two cycles of therapy (Figure 1B). Interestingly, after four cycles of therapy, the lung mass showed further shrinkage, as evidenced by CT scan (Figure 1C). In addition, the expression of carcinoembryonic antigen was reduced progressively in the course of treatment (Table 1).

\section{Case 2}

A 52-year-old woman also presented to Shandong Cancer Hospital. Multiple lung nodules and multiple brain metastases were found in the patient by $\mathrm{CT}$ scan and magnetic resonance imaging scan, respectively (Figures $2 \mathrm{~A}$ and $3 \mathrm{~A}$ ).

Table I Clinical characteristics of different patients during the course of treatment

\begin{tabular}{|c|c|c|c|}
\hline Variable & Case I & Case 2 & Case 3 \\
\hline Age, years & 69 & 52 & 58 \\
\hline Sex & Male & Female & Female \\
\hline Stage & IV & IV & IV \\
\hline Smoking & Yes & No & No \\
\hline \multicolumn{4}{|l|}{ Primary tumor size $(\mathrm{cm})$} \\
\hline Before treatment & $6.0 \times 4.7$ & $1.8 \times 1.2$ & $2.7 \times 2.3$ \\
\hline After two cycles of therapy & $4.4 \times 3.7$ & Show not clear & $1.8 \times 1.0$ \\
\hline After four cycles of therapy & $4.2 \times 3.3$ & Show not clear & $1.0 \times 0.7$ \\
\hline Pathological type & Adenocarcinoma & Adenocarcinoma & Adenocarcinoma \\
\hline \multicolumn{4}{|l|}{ Gene type } \\
\hline EGFR & Wild type & Wild type & Exon 19 mutation \\
\hline ALK & Negative & Positive & Negative \\
\hline \multicolumn{4}{|l|}{ CEA $(n g / m L)$} \\
\hline Before treatment & 419.2 & 119.9 & 8.62 \\
\hline After two cycles of therapy & 244.9 & 25.03 & 3.48 \\
\hline After four cycles of therapy & 189.2 & 14.63 & 1.72 \\
\hline \multicolumn{4}{|l|}{ Response } \\
\hline After two cycles of therapy & PR & $\mathrm{CR}$ & PR \\
\hline After four cycles of therapy & SD & SD & SD \\
\hline
\end{tabular}

Abbreviations: EGFR, epidermal growth factor receptor; ALK, anaplastic lymphoma kinase; CEA, carcinoembryonic antigen; PR, progressive disease; CR, complete response; SD, stable disease. 

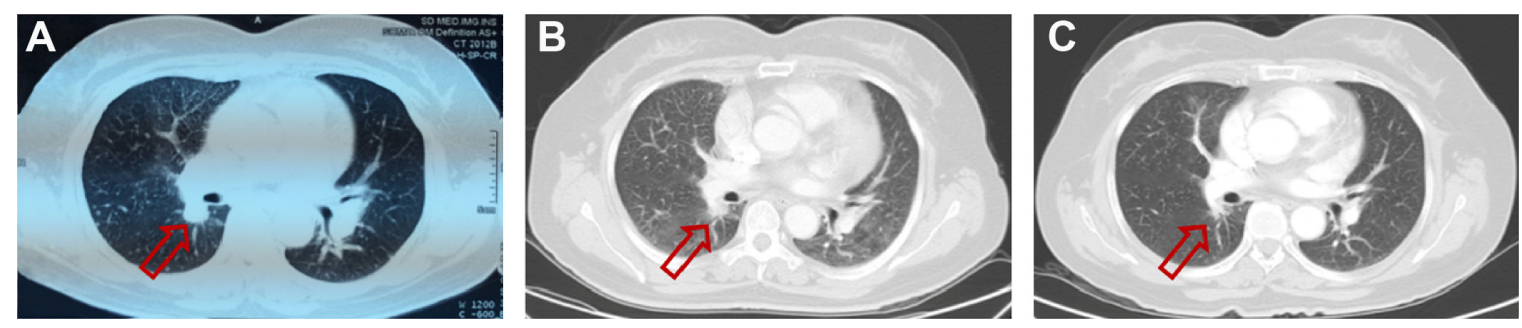

Figure 2 Case 2.

Notes: (A) Prior to therapy, chest CT scan shows a major lung nodule (arrow) in the right lung. (B) After two cycles of therapy, chest CT scan shows significant shrinkage of the mass (arrow). (C) After four cycles of therapy, chest CT scan shows further shrinkage of the mass (arrow).

Abbreviation: $\mathrm{CT}$, computed tomography.

CT-guided percutaneous needle biopsy of the mass proved adenocarcinoma, and the gene detection showed that the EGFR was wild type and the ALK rearrangement was positive. This patient also received bevacizumab $(7.5 \mathrm{mg} / \mathrm{kg})$, cisplatin $\left(75 \mathrm{mg} / \mathrm{m}^{2}\right)$, and pemetrexed $\left(500 \mathrm{mg} / \mathrm{m}^{2}\right)$ administered every 3 weeks. During the treatment, digestive tract reaction and myelotoxicity were well tolerated. Chest CT showed significant shrinkage of the major lung nodule after two cycles of therapy (Figure 2B). Importantly, brain magnetic resonance imaging showed that the major brain metastasis mass almost disappeared after two cycles of therapy (Figure 3B). Similarly, after four cycles of therapy, the major lung nodule showed further shrinkage as seen from CT scan (Figure 2C), and the brain metastasis mass also almost disappeared (Figure 3C). In addition, the expression of carcinoembryonic antigen was reduced progressively in the course of treatment (Table 1).

\section{Case 3}

A 58-year-old woman also presented to Shandong Cancer Hospital. The left lung mass was found by CT scan 3 months ago (Figure 4A). CT-guided percutaneous needle biopsy of the lung mass proved adenocarcinoma, and the gene detection showed that a deletion mutation in the exon 19 of the EGFR and the ALK rearrangement was negative. She also received bevacizumab $(7.5 \mathrm{mg} / \mathrm{kg})$, cisplatin $\left(75 \mathrm{mg} / \mathrm{m}^{2}\right)$, and pemetrexed $\left(500 \mathrm{mg} / \mathrm{m}^{2}\right)$ administered every 3 weeks. During the treatment, digestive tract reaction and myelotoxicity were also well tolerated. Chest $\mathrm{CT}$ showed significant shrinkage of the major lung nodule after two cycles of therapy (Figure 4B). Similarly, after four cycles of therapy, the major lung nodule showed further shrinkage as seen from CT scan (Figure 4C). The expression of carcinoembryonic antigen was also reduced progressively in the course of treatment (Table 1).

\section{Discussion}

The vascular endothelial growth factor pathway is well established as one of the key regulators in tumor angiogenesis, which is a fundamental event in tumor growth and metastatic dissemination. ${ }^{10,11}$ Bevacizumab, a recombinant humanized IgG1 monoclonal antibody, can inhibit tumor angiogenesis and suppress tumor growth and metastasis by
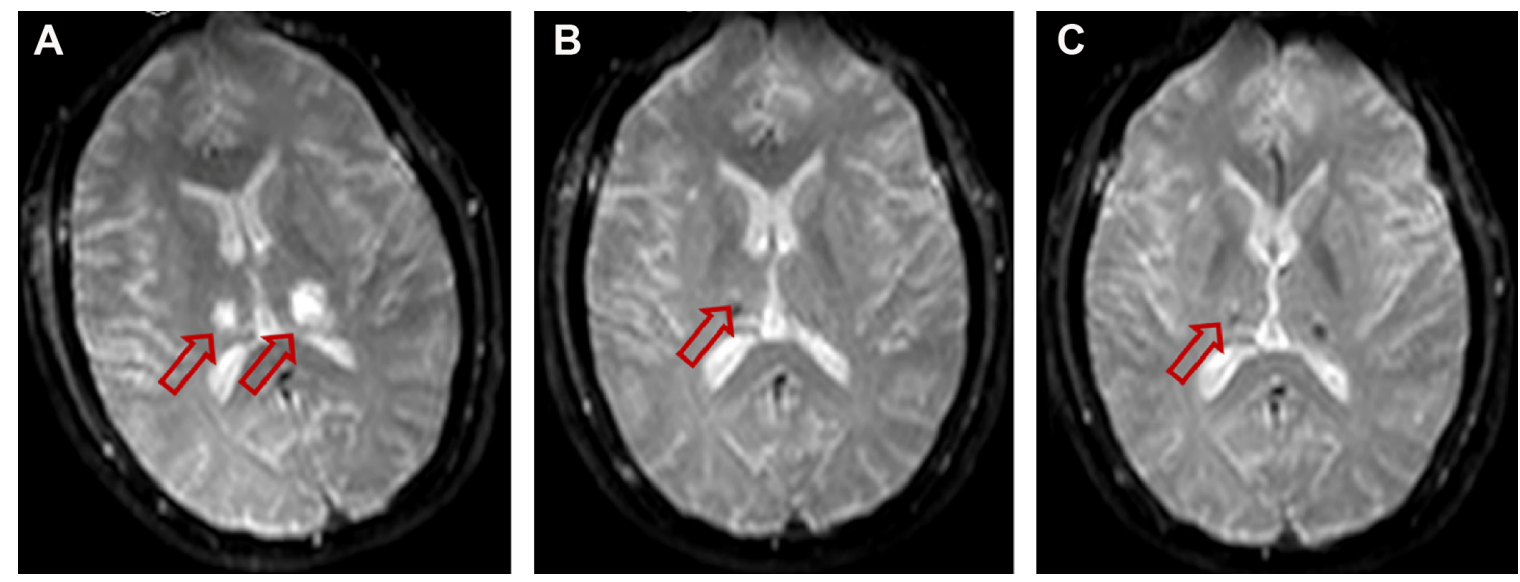

Figure 3 Case 2 .

Notes: (A) Prior to therapy, brain MRI scan shows major brain metastasis nodules (arrow). (B and C) After two or four cycles of therapy, brain MRI scan shows significant shrinkage of the major brain metastasis nodules (arrow).

Abbreviation: MRI, magnetic resonance imaging. 

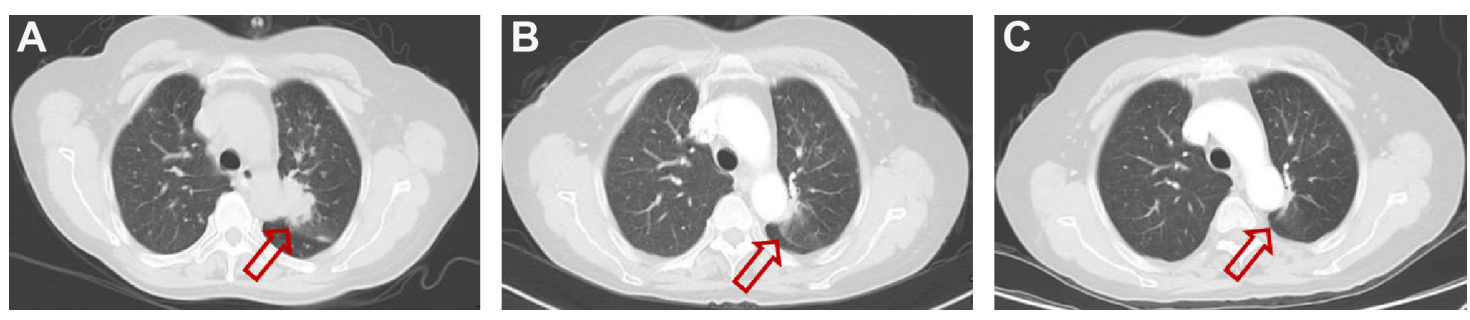

Figure 4 Case 3.

Notes: (A) Prior to therapy, chest CT scan shows a major lung mass (arrow) in the right lung. (B) After two cycles of therapy, chest CT scan shows significant shrinkage of the mass (arrow). (C) After four cycles of therapy, chest CT scan shows further shrinkage of the mass (arrow).

Abbreviation: CT, computed tomography.

specifically binding with vascular endothelial growth factor, thereby blocking the biological effects of vascular endothelial growth factor. ${ }^{12}$ In addition, bevacizumab can increase the concentration of chemotherapeutic drug by promoting tumor vascular stabilization, reducing tissue gap pressure, and increasing vascular permeability, thus enhancing the efficacy of chemotherapy. ${ }^{13}$

At present, bevacizumab showed encouraging efficacy as the first-line therapy for patients with nonsquamous NSCLC in some studies (Table 2). The Eastern Cooperative Oncology Group 4599, a Phase III clinical study of III/IV nonsquamous NSCLC, compared the efficacy of carboplatin/paclitaxel and carboplatin/paclitaxel plus bevacizumab and showed that the median OS was extended by 2 months and the median PFS was extended by 1.7 months, respectively. ${ }^{14}$ The AVAiL compared the efficacy of cisplatin/gemcitabine and cisplatin/gemcitabine plus bevacizumab for advanced NSCLC and showed that the hazard ratio for PFS was 0.75 in the low-dose group and 0.82 in the high-dose group compared with placebo, respectively. ${ }^{15}$ Reynolds et al evaluated the combination of nab-paclitaxel, carboplatin, and bevacizumab in advanced (stage IIIB/IV) nonsquamous NSCLC and showed the response rate was $31 \%$ with a stable disease rate of $54 \%$. The median PFS was 9.8 months, and the median OS was 16.8 months. ${ }^{16}$ The SAiL study, an open-label, single-group, Phase IV study from centers in 40 countries, assessed the safety and efficacy of first-line bevacizumab combined with standard chemotherapy regimens in clinical practice and confirmed the manageable safety profile of first-line bevacizumab in combination with various standard chemotherapy regimens for the treatment of advanced nonsquamous NSCLC. ${ }^{17}$ Interestingly, these studies considered mainly White patients as the research subjects. In fact, bevacizumab was also efficacious in Asian populations by subgroup analyses of the AVAiL and SAiL studies. In addition, the randomized Phase II JO19907 study compared the efficacy and safety of first-line carboplatin/paclitaxel alone with carboplatin/paclitaxel plus bevacizumab in Japanese patients with advanced nonsquamous NSCLC. The results showed that the hazard ratio for PFS was 0.61 with carboplatin/paclitaxel plus bevacizumab versus carboplatin/paclitaxel alone. ${ }^{18}$

Table 2 Randomized controlled trials of bevacizumab plus chemotherapy

\begin{tabular}{|c|c|c|c|c|}
\hline Study ID & Published year & Chemotherapy regimens & Results & Research type \\
\hline Sandler et al $^{14}$ & 2006 & Paclitaxel/carboplatin & $\begin{array}{l}\text { The median survival was } 12.3 \text { months and } 10.3 \text { months } \\
(P=0.003) \text {. The median PFS was } 6.2 \text { months and } \\
4.5 \text { months }(P<0.00 \mathrm{I})\end{array}$ & Prospective study \\
\hline Reck et al ${ }^{15}$ & 2009 & Cisplatin/gemcitabine & The PFS was 6.7 months and 6.1 months $(P=0.003)$ & Prospective study \\
\hline Reynolds et al ${ }^{16}$ & 2009 & Paclitaxel/carboplatin & $\begin{array}{l}\text { Median PFS was } 9.8 \text { months, and median survival was } \\
16.8 \text { months }\end{array}$ & Prospective study \\
\hline Crinò et al ${ }^{17}$ & 2010 & $\begin{array}{l}\text { Platinum-based } \\
\text { chemotherapy }\end{array}$ & $\begin{array}{l}\text { Confirm the manageable safety profile of first-line } \\
\text { bevacizumab in combination with various standard } \\
\text { chemotherapy regimens }\end{array}$ & Prospective study \\
\hline Niho et al ${ }^{18}$ & 2012 & Carboplatin/paclitaxel & $\begin{array}{l}\text { The median PFS was } 6.9 \text { months and } 5.9 \text { months } \\
(P=0.0090) \text {. Median OS was }>22 \text { months in both } \\
\text { treatment groups }(P=0.9526)\end{array}$ & Prospective study \\
\hline Zhou et al ${ }^{19}$ & 2015 & Carboplatin/paclitaxel & $\begin{array}{l}\text { OS was } 24.3 \text { months and } 17.7 \text { months }(P=0.0154) \text {. } \\
\text { Median PFS was } 12.4 \text { months and } 7.9 \text { months }(P<0.001)\end{array}$ & Prospective study \\
\hline Mir et $\mathrm{al}^{23}$ & 2012 & Pemetrexed/oxaliplatin & $\begin{array}{l}\text { The median PFS and OS were } 6.2 \text { months and } \\
14.6 \text { months, respectively }\end{array}$ & Prospective study \\
\hline
\end{tabular}

Abbreviations: PFS, progression-free survival; OS, overall survival. 
Importantly, the Phase III BEYOND trial was undertaken to confirm the efficacy of first-line bevacizumab plus platinum doublet chemotherapy in a Chinese patient population, and the results showed that the PFS was prolonged by 2.7 months and the OS was also prolonged by 6.6 months in patients with carboplatin/paclitaxel plus bevacizumab versus carboplatin/ paclitaxel plus placebo. ${ }^{19}$ After reviewing the earlier research, we can find that bevacizumab combined with chemotherapy has been used as the first-line therapy status for advanced nonsquamous lung cancer. However, two problems should be paid attention. First, bevacizumab can prolong survival only in combination with paclitaxel, and the survival benefits to patients were not found in combination with gemcitabine. This can be attributed to the fact that paclitaxel can trigger inflammation in the body, thus promoting the formation of tumor blood vessels. ${ }^{20,21}$ Interestingly, bevacizumab, an antiangiogenic drug, not only can reverse these negative factors but also can augment the treatment effect of paclitaxel. Second, pemetrexed, an effective therapeutic agent in the treatment of NSCLC, is a novel metabolic antagonist capable of inhibiting multiple enzymes involved in folate metabolism. At present, cisplatin plus pemetrexed therapy has been used as a standard therapeutic strategy for patients with advanced nonsquamous NSCLC. ${ }^{22}$ However, few studies have focused on cisplatin/pemetrexed with bevacizumab as the firstline therapy to treat advanced nonsquamous NSCLC. Similar studies have been analyzed, and we found the application of combination of pemetrexed/oxaliplatin and bevacizumab in patients with stage IV NSCLC and showed that the objective response rate was $55.3 \%$. The median PFS and OS were 6.2 months and 14.6 months, respectively. ${ }^{23}$ However, in this study, the application of bevacizumab is combined with oxaliplatin and not with cisplatin. In addition, Barlesi et $\mathrm{al}^{24}$ demonstrated that in patients with nonsquamous NSCLC who had achieved disease control with platinum-based chemotherapy plus bevacizumab, bevacizumab plus pemetrexed maintenance was associated with a significant PFS benefit compared with bevacizumab alone. However, the study was not from the People's Republic of China, and the study did not carry out subgroup analysis according to different gene mutation types. Hirai et $\mathrm{a}^{25}$ also retrospectively evaluated the feasibility of cisplatin/pemetrexed/bevacizumab therapy as a first-line chemotherapeutic strategy for patients with advanced nonsquamous NSCLC and clarified the effectiveness and tolerability of cisplatin/pemetrexed/bevacizumab therapy in patients with nonsquamous NSCLC. However, the study was also not from the People's Republic of China, and the dose of bevacizumab was $15 \mathrm{mg} / \mathrm{kg}$ in this study. In our study, we mainly proved the effectiveness of cisplatin/pemetrexed/ bevacizumab therapy in Chinese patients with nonsquamous NSCLC, irrespective of the gene drive type. In addition, the dose of bevacizumab that all the patients received was $7.5 \mathrm{mg} / \mathrm{kg}$ in our study. However, these are just a few case reports, and it requires a larger, randomized controlled trial to verify.

The discovery of EGFR mutations or ALK rearrangements has led to altered treatments for patients with NSCLC who harbor these drivers. Agents that inhibit the tyrosine kinase-binding sites have demonstrated improved PFS versus chemotherapy. However, the correlation between EGFR mutations or ALK rearrangements and the efficacy of bevacizumab in combination with chemotherapy warrants further analysis. The BEYOND trial showed the significance of high EGFR tyrosine kinase inhibitor in both arms after progression, but overall postprogression treatments were balanced in the EGFR mutation-positive group. EGFR mutation-positive tumor status seemed to be prognostic for a better prognosis regardless of treatment. The median PFS was 12.4 months with carboplatin/paclitaxel plus bevacizumab and 7.9 months with carboplatin/paclitaxel plus placebo in EGFR mutationpositive tumors and 8.3 months and 5.6 months in wild-type tumors, respectively. ${ }^{19}$ Interestingly, another study showed that ALK-positive patients had a significantly longer PFS on pemetrexed compared with EGFR or KRAS mutant patients in NSCLC. This conclusion suggested that pemetrexed should be preferentially considered for the treatment of ALK-positive lung adenocarcinoma. ${ }^{26}$ In our study, we chose three patients with different types of gene drives and found that the disease in the three patients was controlled. However, we also found the disease remission of the first patient is relatively slow compared to the other two patients. This phenomenon may be due to different driving genes. Of course, more clinical studies are needed for further clarification.

There are still some limitations in our report. First, at present, the patients in our report are still in the maintenance therapy, and the exact PFS or OS was not observed due to a short span of time. Second, in our report, we mainly evaluated the changes of the main mass in the lung. In fact, different degrees of lymph node metastasis were found in the three patients before treatment, and all these lymph node metastases get relieved to some extent after treatment.

\section{Conclusion}

In summary, based on the three cases and previous studies, cisplatin/pemetrexed/bevacizumab therapy can serve as a primary therapeutic strategy for patients with advanced 
nonsquamous NSCLC and with or without EGFR mutations or ALK rearrangements. More clinical studies are needed to further validate our hypothesis.

\section{Acknowledgment}

This work was supported by the special fund for Scientific Research in Public Interest (201402011).

\section{Disclosure}

The authors report no conflicts of interest in this work.

\section{References}

1. Jemal A, Bray F, Center MM, Ferlay J, Ward E, Forman D. Global cancer statistics. CA Cancer J Clin. 2011;61(2):69-90.

2. Liu KJ, Guan ZZ, Liang Y, et al. A double-blind, randomized phase II study of dicycloplatin plus paclitaxel versus carboplatin plus paclitaxel as first-line therapy for patients with advanced non-small-cell lung cancers. Arch Med Sci. 2014;10(4):717-724.

3. Stinchcombe TE, Socinski MA. Current treatments for advanced stage non-small cell lung cancer. Proc Am Thorac Soc. 2009;6(2): 233-241.

4. Hotta K, Matsuo K, Ueoka H, Kiura K, Tabata M, Tanimoto M. Addition of platinum compounds to a new agent in patients with advanced nonsmall-cell lung cancer: a literature based meta-analysis of randomised trials. Ann Oncol. 2004;15(12):1782-1789.

5. Schiller JH, Harrington D, Belani CP, et al. Comparison of four chemotherapy regimens for advanced non-small-cell lung cancer. $N$ Engl $J$ Med. 2002;346(2):92-98.

6. Ohe Y, Ohashi Y, Kubota K, et al. Randomized phase III study of cisplatin plus irinotecan versus carboplatin plus paclitaxel, cisplatin plus gemcitabine and cisplatin plus vinorelbine for advanced non-small-cell lung cancer: Four-Arm Cooperative Study in Japan. Ann Oncol. 2007; 18(2):317-323.

7. Perez-Soler R, Chachoua A, Hammond LA, et al. Determinants of tumor response and survival with erlotinib in patients with non-small-cell lung cancer. J Clin Oncol. 2004;22(16):3238-3247.

8. Kris MG, Natale RB, Herbst RS, et al. Efficacy of gefitinib, an inhibitor of the epidermal growth factor receptor tyrosine kinase, in symptomatic patients with non-small cell lung cancer: a randomized trial. JAMA. 2003; 290(16):2149-2158.

9. Cohen MH, Gootenberg J, Keegan P, Pazdur R. FDA drug approval summary: bevacizumab (Avastin) plus Carboplatin and Paclitaxel as first-line treatment of advanced/metastatic recurrent nonsquamous non-small cell lung cancer. Oncologist. 2007;12(6):713-718.

10. Ferrara N. Role of vascular endothelial growth factor in physiologic and pathologic angiogenesis: therapeutic implications. Semin Oncol. 2002;29(suppl 16):10-14.

11. Bergers G, Benjamin LE. Tumorigenesis and the angiogenic switch. Nat Rev Cancer. 2003;3(6):401-410.

12. Jenab-Wolcott J, Giantonio BJ. Bevacizumab. current indications and future development for management of solid tumors. Expert Opin Biol Ther. 2009;9(4):507-517.

OncoTargets and Therapy

\section{Publish your work in this journal}

OncoTargets and Therapy is an international, peer-reviewed, open access journal focusing on the pathological basis of all cancers, potential targets for therapy and treatment protocols employed to improve the management of cancer patients. The journal also focuses on the impact of management programs and new therapeutic agents and protocols on

Submit your manuscript here: http://www.dovepress.com/oncotargets-and-therapy-journal
13. Willett GG, Boucher Y, di Tomaso E, et al. Direct evidence that the VEGF-specific antibody bevacizumab has antivascular effects in human rectal cancer. Nat Med. 2004;10(2):145-147.

14. Sandler A, Gray R, Perry MC, et al. Paclitaxel-carboplatin alone or with bevacizumab for non-small-cell lung cancer. N Engl J Med. 2006; 355(24):2542-2550.

15. Reck M, von Pawel J, Zatloukal P, et al. Phase III trial of cisplatin plus gemcitabine with either placebo or bevacizumab as first-line therapy for nonsquamous non-small-cell lung cancer: AVAil. J Clin Oncol. 2009;27(8):1227-1234.

16. Reynolds C, Barrera D, Jotte R, et al. Phase II trial of nanoparticle albumin-bound paclitaxel, carboplatin, and bevacizumab in first-line patients with advanced nonsquamous non-small cell lung cancer. J Thorac Oncol. 2009;4(12):1537-1543.

17. Crinò L, Dansin E, Garrido P, et al. Safety and efficacy of first-line bevacizumab-based therapy in advanced non-squamous non-small-cell lung cancer (SAiL, MO19390): a phase 4 study. Lancet Oncol. 2010; 11(8):733-740.

18. Niho S, Kunitoh H, Nokihara H, et al. Randomized phase II study of first-line carboplatin-paclitaxel with or without bevacizumab in Japanese patients with advanced non squamous non-small-cell lung cancer. JO19907 Study Group. Lung Cancer. 2012;76(3):362-367.

19. Zhou C, Wu YL, Chen G, et al. BEYOND: a randomized, doubleblind, placebo-controlled, multicenter, phase III study of first-line carboplatin/paclitaxel plus bevacizumab or placebo in Chinese patients with advanced or recurrent nonsquamous non-small-cell lung cancer. J Clin Oncol. 2015;33(19):2197-2204.

20. Roodhart JM, He H, Daenen LG, et al. Notch1 regulates angio-supportive bone marrow-derived cells in mice: relevance to chemoresistance. Blood. 2013;122(1):143-153.

21. Volk-Draper L, Hall K, Griggs C, et al. Paclitaxel therapy promotes breast cancer metastasis in a TLR4-dependent manner. Cancer Res. 2014; 74(19):5421-5434.

22. Scagliotti GV, Parikh P, von Pawel J, et al. Phase III study comparing cisplatin plus gemcitabine with cisplatin plus pemetrexed in chemotherapy-naive patients with advanced-stage non-small-cell lung cancer. J Clin Oncol. 2008;26(21):3543-3551.

23. Mir O, Boudou-Rouquette P, Giroux J, et al. Pemetrexed, oxaliplatin and bevacizumab as first-line treatment in patients with stage IV nonsmall cell lung cancer. Lung Cancer. 2012;77(1):104-109.

24. Barlesi F, Scherpereel A, Rittmeyer A, et al. Randomized phase III trial of maintenance bevacizumab with or without pemetrexed after first-line induction with bevacizumab, cisplatin, and pemetrexed in advanced nonsquamous non-small-cell lung cancer: AVAPERL (MO22089). J Clin Oncol. 2013;31(24):3004-3011.

25. Hirai F, Seto T, Inamasu E, et al. Feasibility of cisplatin/pemetrexed with $15 \mathrm{mg} / \mathrm{kg}$ bevacizumab for the treatment of patients with advanced nonsquamous non-small cell lung cancer. Oncol Lett. 2015;9(6):2577-2582.

26. Camidge DR, Kono SA, Lu X, et al. Anaplastic lymphoma kinase gene rearrangements in non-small cell lung cancer are associated with prolonged progression-free survival on pemetrexed. J Thorac Oncol. 2011; 6(4):774-780.

patient perspectives such as quality of life, adherence and satisfaction. The manuscript management system is completely online and includes a very quick and fair peer-review system, which is all easy to use. Visit http://www.dovepress.com/testimonials.php to read real quotes from published authors. 